\title{
Profiling Rat Brain Monoacylglycerol Lipase Activity Using an Ammonia- Adduct Enhanced Selected Ion Monitoring Liquid-Chromatography Positive Electrospray Ionization Mass Spectrometry Assay
}

\section{Gary W Caldwell* and Wensheng Lang}

Janssen Pharmaceutical Companies of Johnson and Johnson, Welsh and McKean Roads, Spring House, PA 19477, USA

\begin{abstract}
2-Arachidonoylglycerols (2-AG) is one of the major endocannabinoids in the central nervous system. Upregulation of central endocannabinoids signaling by selective inhibition of brain monoacylglycerol lipase (MAGL) activity is a potential therapeutic approach in pain, obesity, and diabetes modulation to name a few. Thus, a sensitive and reliable analytical method for determination of endocannabinoid levels in the brain is essential for the discovery of MAGL inhibitors. Accurate measurement of monoacylglycerols (MAG) levels, using liquid chromatography positive electrospray ionization mass spectrometry (LC / +ESI / MS) and tandem MS, is a challenge since the brain endocannabinoids are not only susceptible to stress in the in-life phase of the study, but also prone to postmortem metabolism, acyl migration (i.e., conversion from 2-MAG to 1(3)-MAG), metal adduct ion formation and chemical hydrolysis generating the same products as those by the target enzyme. To avoid these artifacts, we have developed a simple LC / +ESI / MS method for direct detection of ammonium-adduct cations of the major MAGs in selected ion monitoring mode (SIM). For the in vitro MAGL inhibition assay, a LC isocratic elution was used for baseline separation of MAGs and their acyl migration isomers produced during the $37^{\circ} \mathrm{C}$ incubation with rat brain homogenate. To minimize the postmortem metabolism and isomerization of MAGs for in-vivo studies, rat brain was homogenized directly in four milliliters of ethanol for every gram of brain tissue and a linear LC gradient elution was applied for broad endocannabinoid profiling. The SIM LC / +ESI / MS method is shown to be useful for in-vitro brain evaluation of inhibitory potency of MAGL and fatty acid amide hydrolase (FAAH) inhibitors and for in-vivo brain assessment for target engagement studies.
\end{abstract}

Keywords: Monoacylglycerol lipase (MAGL) anandamide or $\mathrm{N}$-arachidonoylethanolamide (AEA); 2-arachidonoylglycerols (2AG); Liquid chromatography and positive electrospray ionization mass spectrometry (LC / +ESI / MS); Selected ion monitoring (SIM); Ammonia adducts

Abbreviations: ECS: Endocannabinoid System; CNS: Central Nervous System; AA: Arachidonic Acid; $\mathrm{CB}_{1}$ : Cannabinoid Receptor Type-1; $\mathrm{CB}_{2}$ : Cannabinoid Receptor Type-2; MAGL: Monoacylglycerol Lipase; OEA: N-Oleoylethanolamide; PEA: N-Palmitoylethanolamide; 2-AGE: 2-Arachidonoylglyceryl Ether; NADA: N-Arachidonoyldopamine; 2-LG: 2-Linoleoylglycerol; 2-PG: 2-Palmitoylglycerol; 2-AG: 2-Arachidonoylglycerol; 1(3)AG: 1-Arachidonoylglycerol; 2-OG: 2-Oleoylglycerol; 1(3)-OG: 1-Oleoylglycerol; AEA: N-Arachidonoylethanolamide; DAGL: DiacylglycerolLipase;NAPE-PLD:N-AcylphosphatidylEthanolaminesPhospholipase D; EMT: Endocannabinoid Membrane Transporters; FABP: Fatty Acid Binding Proteins; FAAH: Fatty Acid Amide Hydrolase; MAG: Monoacylglycerol; URB597: 3'-((Aminocarbonyl) [1,1'-Biphenyl]-3-yl)-Cyclohexylcarbamate; URB602: ([1,1-Biphenyl] -3-yl)-Carbamic Acid, Cyclohexyl Ester; MAFP: Methyl Arachidonyl Fluorophosphate; GC / MS: Gas Chromatography Mass Spectrometry; LC / MS: Liquid Chromatography Mass Spectrometry; +ESI: Positive Electrospray Ionization; SIM: Selected Ion Monitoring; MS / MS: Tandem Mass Spectrometry / Mass Spectrometry; CID: CollisionInduced Dissociation; MRM: Multiple Reaction Monitoring; $\mathrm{m} / z$ : mass-to-charge ratio

\section{Introduction}

The endocannabinoid system (ECS) has involvement in the signaling network of physiological processes in both the central nervous system (CNS) and peripheral tissues and thus, plays an important role in disorders of the CNS [1], in the immune system [2,3], in energy homeostasis [4], in inflammatory pain [5] and in the cardiovascular system of mammals [6]. The ECS consists of the endocannabinoids, type- 1 and type- $2 \mathrm{G}$ protein-coupled cannabinoid receptors (i.e., $\mathrm{CB}_{1}$ and $\mathrm{CB}_{2}$ ), transporters, and enzymes that tightly regulate biosynthesis and degradation of endocannabinoids (Figure 1) $[3,7,8]$. Endocannabinoids are lipophilic arachidonic acid (AA) derivative transmitters that are generated and released in different organs and tissues by lipases. While there are many endocannabinoids that bind to $\mathrm{CB}_{1}$ and $\mathrm{CB}_{2}$ receptors including $\mathrm{O}$-arachidonoylethanolamine (virodhamine), 2-arachidonoylglyceryl ether (2-AGE, noladin ether), $\mathrm{N}$-arachidonoyldopamine (NADA), and 2-oleoylglycerol (2OG), the two best characterized brain endocannabinoids are $\mathrm{N}$-arachidonoylethanolamide (AEA; anandamide) a polyunsaturated fatty acid amide formed by ethanolamine bound to a fatty acid with 20 carbons and 2-arachidonoylglycerol (2-AG), an ester formed by AA and glycerol [9]. Other endocannabinoid congeners show cannabimimetic activity without binding to $\mathrm{CB}_{1}$ and $\mathrm{CB}_{2}$ receptors (i.e., entourage

*Corresponding author: Gary W Caldwell, Johnson and Johnson Pharmaceutical Research and Development, L.L.C. Drug Discovery Department Welsh and McKean Roads, P.O. Box 776, Spring House, PA 19477, USA, Tel: +1-732-524-6678; E-mail: GCaldwel@its.jnj.com

Received March 02, 2016; Accepted March 17, 2016; Published March 20, 2016

Citation: Caldwell GW, Lang W (2016) Profiling Rat Brain Monoacylglycerol Lipase Activity Using an Ammonia-Adduct Enhanced Selected Ion Monitoring LiquidChromatography Positive Electrospray Ionization Mass Spectrometry Assay. Pharm Anal Acta 7: 470. doi:10.4172/2153-2435.1000470

Copyright: (c) 2016 Tarro G. This is an open-access article distributed under the terms of the Creative Commons Attribution License, which permits unrestricted use, distribution, and reproduction in any medium, provided the original author and source are credited. 
Citation: Caldwell GW, Lang W (2016) Profiling Rat Brain Monoacylglycerol Lipase Activity Using an Ammonia-Adduct Enhanced Selected lon Monitoring Liquid-Chromatography Positive Electrospray lonization Mass Spectrometry Assay. Pharm Anal Acta 7: 470. doi:10.4172/21532435.1000470

Page 2 of 11

effect) including 2-linoleoylglycerol (2-LG), 2-palmitoylglycerol (2PG), N-oleoylethanolamide (OEA), and N-palmitoylethanolamide (PEA); this entourage effect occurs by these congeners potentiating the apparent binding of 2-AG, AEA and other endocannabinoids [10,11]. $2-\mathrm{AG}$ is biosynthesized on demand utilizing diacylglycerol congeners and calcium activated diacylglycerol lipase (DAGL) whereas AEA is biosynthesized on demand utilizing $\mathrm{N}$-acylphosphatidylethanolamine and N-acylphosphatidylethanolamines-phospholipase D(NAPE-PLD). Both 2-AG and AEA are released from the cell into intercellular spaces via a passive membrane transport mechanism [3]. Endocannabinoids that bind to $\mathrm{CB}_{1}$ and $\mathrm{CB}_{2}$ receptors can be full, partial, and inverse agonists, and have functional selectivity. $\mathrm{CB}_{1}$ receptors are present in very high levels in several brain regions including the CNS presynaptic nerve terminals where their activation brings about a decrease in neurotransmission. $\mathrm{CB}_{2}$ receptors have a more restricted distribution, being found in a number of immune cells in the periphery and act to modulate immune function [12-14]. In addition, endocannabinoids can activate other non-cannabinoid receptors including the orphan G protein-coupled receptor 55 (GPR55), peroxisome proliferatoractivated receptors- $\gamma$ (PPAR- $\gamma$ ), transient receptor potential vanilloid- 1 channels (TRPV1), and $\gamma$-aminobutyric acid receptor A $\left(\mathrm{GABA}_{\mathrm{A}}\right)$ [3]. AEA and 2-AG are rapidly up-taken into cells by a passive membrane transport mechanism or by endocannabinoid membrane transporters (EMT) followed by inactivation by hydrolysis. The EMTs in the brain are mediated by the fatty acid binding proteins (FABP5 / FABP7) [15]. The enzyme involved in AEA hydrolysis is the fatty acid amide hydrolase (FAAH) that produces AA and ethanolamine. The major enzyme involved in 2-AG and other monoacylglycerols (MAG) hydrolysis is monoacylglycerol lipase (MAGL) that produces AA and glycerol [16-
20]. It should be noted that the hydrolysis of 2-AG is more complicated than depicted in Figure 1 since MAGL accounts for approximately 50\% of the 2-AG hydrolysis activity in brain thus, implying the existence of additional 2-AG hydrolyzing enzymes including contribution by the $\alpha / \beta$-hydrolase domain (ABHD) proteins (i.e., ABHD6 and ABHD12) $[21,22]$.

The balance between AEA and 2-AG biosynthesis and inactivation determines their accumulation in tissues and thus, their biological activity. Therefore, for the past decade, the modulation of AEA and 2-AG levels in biological fluids and tissues through the binding of small molecule inhibitors to FAAH and MAGL enzymes has been a therapeutic strategy for a number of diseases including pain, schizophrenia, stroke, obesity, Alzheimer's disease, multiple sclerosis, and cancer, to name just a few [1-6,23-25]. Several small molecule reversible and irreversible inhibitors for FAAH and MAGL have been discovered with the numbers of selective FAAH inhibitors exceeding those of MAGL inhibitors [26-29]. Many drug-design strategies for inhibitors of FAAH and MAGL have been inspired by the chemical structures of their substrates AEA and 2-AG, respectively. For example, an early selective irreversible inhibitor for FAAH was 3'-((aminocarbonyl)[1, 1'-biphenyl]-3-yl)-cyclohexylcarbamate (URB597) where the biphenyl substituent mimics the arachidonoyl chain of AEA [30,31]. It has been shown that the URB597 carbamate-based inhibitor undergoes hydrolysis in the active site of FAAH. In this case, the FAAH enzyme was covalently modified by the cyclohexyl moiety of URB597 with the biphenyl substituent serving as the leaving group [28]. The inversion of the biphenyl and the cyclohexyl substituents across the carbamate group eliminates FAAH inhibition and enables MAGL inhibition. Thus, the carbamate-based compound ([1,1-biphenyl]-3-yl)-carbamic

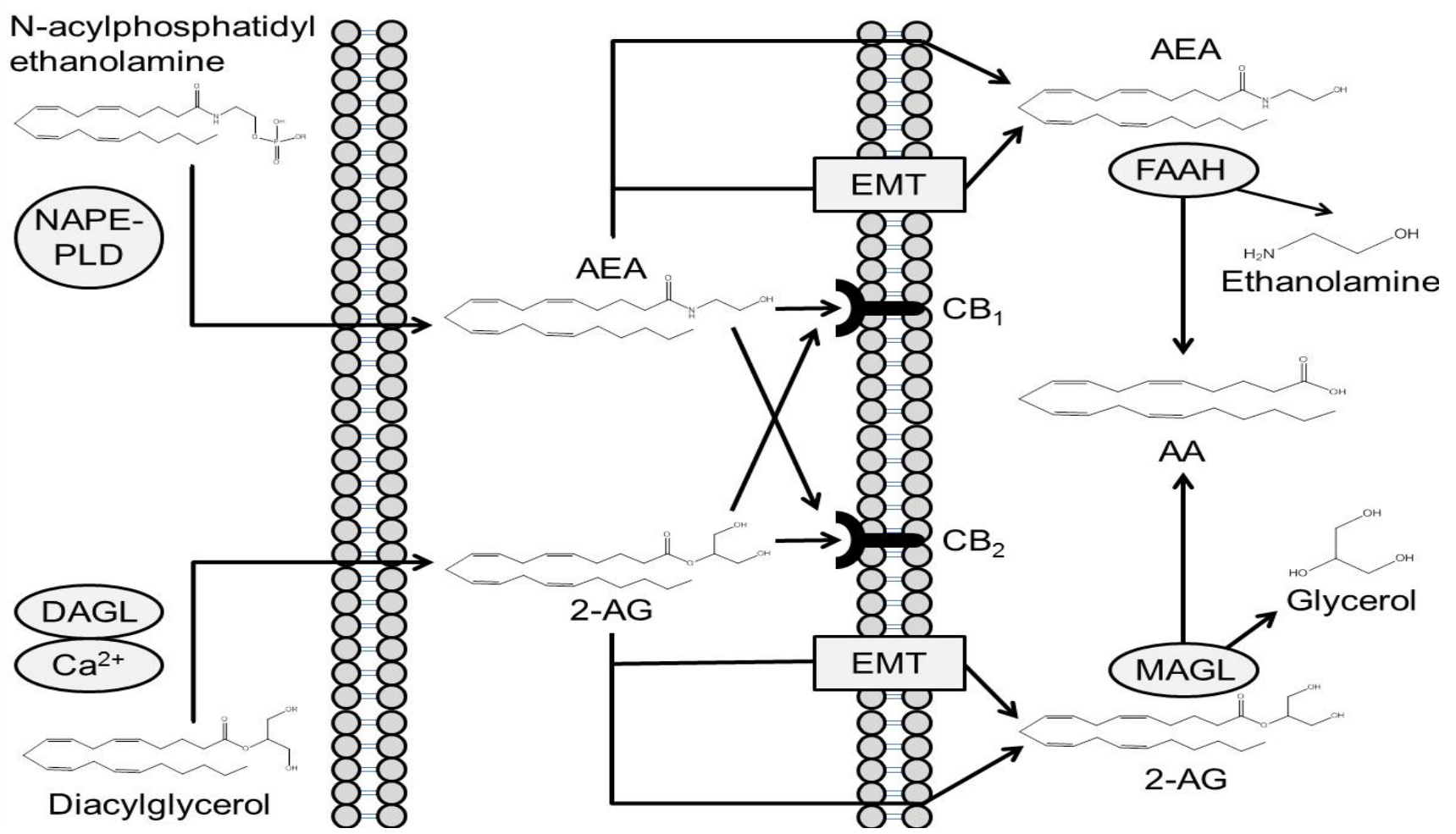

Figure 1: Schematic representation of the endocannabinoid system (ECS). AEA, N-Arachidonoylethanolamide or Anandamide; 2-AG, 2-Arachidonoylglecerol; MAGL, Monoacylglycerol Lipase; FAAH, Fatty Acid Amide Hydrolase; DAGL, Diacylglycerol Lipase; NAPE-PLD, N Acylphosphatidylethanolamines-Phospholipase D; EMT, Endocannabinoid Membrane Transporter; $\mathrm{CB}_{1}$ and $\mathrm{CB}_{2}$ Cannabinoid Receptors. 
Citation: Caldwell GW, Lang W (2016) Profiling Rat Brain Monoacylglycerol Lipase Activity Using an Ammonia-Adduct Enhanced Selected lon Monitoring Liquid-Chromatography Positive Electrospray lonization Mass Spectrometry Assay. Pharm Anal Acta 7: 470. doi:10.4172/21532435.1000470

acid, cyclohexyl ester (URB602) was discovered to be a selective noncompetitive partially reversible inhibitor for MAGL [32]. Methyl arachidonyl fluorophosphate (MAFP) is an example of a non-selective FAAH and MAGL irreversible inhibitor that contains an arachidonoyl chain [33]. URB597, URB602, and MAFP are typically used as positive and negative controls for FAAH and MAGL activity assays, respectively [26-29].

To discover inhibitors of FAAH and MAGL, sensitive and specific analytical methods are required to measure concentration levels of endocannabinoids in biological fluids and tissues. Gas and liquid chromatography mass spectrometry (i.e., GC / MS and LC / MS) [34-36] and GC and LC tandem mass spectrometry (i.e., GC / MS / MS and LC / MS / MS) [37-39] approaches have been successful for quantitative analysis of endocannabinoid levels. Concentration of endocannabinoids in biological matrices are usually quantified by isotope dilution techniques, using either mass-to-charge ratio $(\mathrm{m} / \mathrm{z})$ endocannabinoid fragment cations, the molecular $(\mathrm{M}+\mathrm{H})^{+}$cation or other adduct $(\mathrm{M}+\mathrm{X})^{+}\left(\mathrm{X}=\mathrm{Na}, \mathrm{K}, \mathrm{NH}_{4}\right.$, etc. $)$ cations where $\mathrm{M}$ denotes the molecular weight of the endocannabinoid. GC / MS and GC / MS / MS methods are typically less utilized for quantitation of endocannabinoids since these techniques require time-consuming procedures including derivatization of the lipid extracts along with reaction purification steps $[34,35,37]$. Thus, LC techniques are used more frequently than GC methods to eliminate the need for derivatization of the endocannabinoids. The LC / MS technique, in many cases, uses an electrospray ionization source in a positive mode (+ESI) ion source with a single quadrupole mass filter operating in a selected ion monitoring (SIM) mode to measure a specific endocannabinoid $\mathrm{m} / z$ cation. For endocannabinoid quantification, this method (i.e., SIM LC / +ESI ( MS) is frequently considered to be less sensitive and specific than tandem mass spectrometry / mass spectrometry (MS / MS) techniques [40]. The preferred method for endocannabinoid quantification is typically LC / MS / MS utilizing a +ESI with a triple quadrupole mass filter to create MS / MS fragmentation of the $m / z$ molecular $(\mathrm{M}+\mathrm{H})^{+}$ endocannabinoid cation and then to measure specific $\mathrm{m} / z$ fragment cations of the molecular cation [40]. The technique of using a specific $m / z(\mathrm{M}+\mathrm{H})^{+}$cation selected in the $1^{\text {st }}$ stage quadrupole mass filter $(\mathrm{Q} 1)$, creating collision-induced dissociation (CID) $\mathrm{m} / z$ fragment cations in the $2^{\text {nd }}$ stage quadrupole collision cell (Q2) and detecting the unique reaction $\mathrm{m} / \mathrm{z}$ fragment cations in the $3^{\text {rd }}$ stage quadrupole mass filter (Q3) is called multiple reaction monitoring (MRM). Large $\mathrm{m} / z$ signal intensities in Q1 facilitate the detection limits for quantitative methods using SIM and MRM techniques. It should be noted that the signal intensity of molecular $\mathrm{m} / \mathrm{z}$ ions observed utilizing ESI techniques are depended upon the ionization constants (i.e., pKa) of the solutionphase and gas-phase acid / base chemistry of the analytes [41]. Therefore, in +ESI mode, the $\mathrm{m} / \mathrm{z}$ signal intensity of endocannabinoid molecular $(\mathrm{M}+\mathrm{H})^{+}$cations containing a basic nitrogen atom (e.g., AEA, virodhamine, NADA, 2-PG, OEA, PEA) are significantly larger than non-nitrogen containing endocannabinoids (e.g., 2-AG, 1(3)-AG, 2OG, 1(3)-OG, 2-LG, 2-PG, and 2-AGE). Non-nitrogen containing endocannabinoids tend to have larger $\mathrm{m} / \mathrm{z}$ signal intensities from sodium and potassium metal-adduct $(\mathrm{M}+\mathrm{Na})^{+}$and $(\mathrm{M}+\mathrm{K})^{+}$cations, respectively, than molecular $(\mathrm{M}+\mathrm{H})^{+}$cations.

Using LC / MS or LC / MS / MS techniques, it is a challenge to establish a reliable analytical method to minimize the variations in the levels of brain 2-AG and its congeners (i.e., 2-OG, 2-PG, and 2-LG) during sample collection, preparation and analysis. For example, the rat brain 2-AG and other MAGs are susceptible, during sample collection and preparation, to postmortem metabolism, to acyl migration (spontaneous 2-MAG to 1(3)-MAG conversion), and to chemical hydrolysis generating the same products (i.e., AA and glycerol) as those by the target enzyme $[42,43]$. Using a + ESI ion source, $2-A G$ and MAGs tend to form metal-adduct $(\mathrm{M}+\mathrm{X})^{+}(\mathrm{X}=$ $\mathrm{Na}, \mathrm{K}) \mathrm{m} / z$ cations with greater ion intensity than molecular $(\mathrm{M}+\mathrm{H})^{+}$ $\mathrm{m} / \mathrm{z}$ cations. The $\mathrm{m} / \mathrm{z}$ signal intensities of metal-adduct cations can vary significantly from sample-to-sample since they arise from trace levels of sodium and potassium salts contained in the LC mobile phase and on surfaces in the mass spectrometer; thus, the application of MRM and SIM detection and quantification of metal-adduct cations are limited for non-nitrogen containing endocannabinoids. In addition, metal-adduct cations are resistant to CID in the ion source and in the collision cell of a tandem mass spectrometry and thus, the application of CID along with SIM and MRM detection and quantification techniques is sometimes limited. Adding low levels of metal salts, such as, sodium acetate $(0.01 \%)$ in the mobile phase has been reported to improve the sensitivity for quantitation of non-nitrogen containing endocannabinoids utilizing SIM LC / MS techniques by providing a controlled source of $\mathrm{Na}^{+}$cations [44]; however, the introduction of nonvolatile salts in the mobile phase over a relatively short periods of time will typically cause metal ion accumulation in the ESI source and reduce the overall sensitivity of the assay. Since the ECS is an active area of research [1-6,23-30] and LC / MS instrumentation is extremely common in many analytical laboratories, having a reliable LC / MS method that is also sensitive and specific to measure the concentration of 2-AG and its congeners in brain tissues, would be beneficial in efforts to develop MAGL inhibitors for potential therapeutic utilities.

In this article, we have developed and applied a SIM LC / +ESI / MS method for determination of the major endocannabinoids in rat brain for in-vitro and in-vivo evaluation of the inhibitory potency and the target engagement of novel compounds. We describe SIM LC / + ESI / MS methods using an ammonium replacement approach to force non-nitrogen containing endocannabinoid metal-adduct $(\mathrm{M}+$ $\mathrm{X})^{+}(\mathrm{X}=\mathrm{Na}, \mathrm{K})$ cations to an ammonium-adduct $\left(\mathrm{M}+\mathrm{NH}_{4}\right)^{+}$cation formation by adding $50 \mathrm{mM}$ ammonium formate for in-vitro studies and $25 \mathrm{mM}$ ammonium formate for in-vivo studies in the LC mobile phases. The optimized LC conditions to stabilize 2-AG and 2-OG in the sample extracts and the mobile phases were selected to minimize the degradation of these analytes during sample preparation and analysis. The SIM LC / +ESI / MS mode was used for detection of the $\left(\mathrm{M}+\mathrm{NH}_{4}\right)^{+}$ cations and isotope dilution techniques for quantification. This method for brain endocannabinoid profiling can be used not only for in-vitro evaluation of inhibitory potency of MAGL and FAAH inhibitors, but also for in-vivo assessment of target engagement and proof of concept studies. To our knowledge, the application of ammonium-adduct cations in conjunction with SIM LC / +ESI / MS detection for nonnitrogen containing endocannabinoids has not been reported in the literature.

\section{Materials and Methods}

\section{Chemicals}

Arachidonoylethanolamide (AEA), $N$-arachidonoylethanolamide- $\mathrm{d}_{8}$ $\left(\right.$ AEA- $\left.\mathrm{d}_{8}\right), 2$-arachidonoylglycerol (2-AG),2-arachidonoylglycerol- $\mathrm{d}_{8}(2-$ AG- $\left.\mathrm{d}_{8}\right), 3$ '-((aminocarbonyl) [1,1'-biphenyl]-3-yl)-cyclohexylcarbamate (URB597), ([1,1-biphenyl]-3-yl)-carbamic acid, cyclohexyl ester (URB602), and methyl arachidonyl fluorophosphate (MAFP) were purchased from Cayman Chemical (Ann Arbor, MI). 2-oleoylglycerol (2-OG), 1-oleoylglycerol (1(3)-OG), 2-linoleoylglycerol (2-LG), 1-arachidonoylglycerol (1(3)-AG), and ammonium formate were 
Citation: Caldwell GW, Lang W (2016) Profiling Rat Brain Monoacylglycerol Lipase Activity Using an Ammonia-Adduct Enhanced Selected lon Monitoring Liquid-Chromatography Positive Electrospray lonization Mass Spectrometry Assay. Pharm Anal Acta 7: 470. doi:10.4172/21532435.1000470

Page 4 of 11

obtained from Sigma-Aldrich (St. Louis, MO). 2-palmitoylglycerol (2-PG) was purchased from Tocris Bioscience (Ellisville, MO). 1-(1-\{[3-Chloro-6-(trifluoromethyl)-1-benzothiophen-2-yl]carbonyl $\}$ azetidin-3-yl)-4-(1,3-thiazol-4-ylcarbonyl)piperazine (JNJ4218734) was obtained from Janssen Research and Development, LLC (Spring House, PA) [29]. Acetonitrile, water, tetrahydrofuran, chloroform, and methanol and other solvents and reagents were obtained from EMD Chemicals (Gibbstown, NJ). Ethyl alcohol (200 proof) was obtained from PharmacoAAPER (Brookfield, CT)

\section{LC / MS assay}

Agilent 1100 Liquid Chromatographic system (Palo Alto, CA) consisting of a quaternary pump G1311A, a degasser G1322A and an autosampler G1367A was used. A Micromass triple-quadrupole Quattro Micro mass spectrometer (Waters, Beverly, MA) was interfaced with the Agilent LC system through a Z-spray electrospray ion source and was operated in the positive cation mode. The triple-quadrupole Quattro Micro mass spectrometer was configured to operate as a LC / MS by only using Q1. Nitrogen was used as the nebulizing gas, the desolvation gas and the cone curtain gas. The MS source parameters were set as follows: capillary voltage, $3500 \mathrm{~V}$; cone voltage, $10 \mathrm{~V}-15$ $\mathrm{V}$; extractor voltage, $2 \mathrm{~V}$; source temperature, $120^{\circ} \mathrm{C}$; desolvation temperature, $250^{\circ} \mathrm{C}$; cone gas flow, $100 \mathrm{~L} / \mathrm{h}$; and desolvation gas flow, $700 \mathrm{~L} / \mathrm{h}$. SIM was applied for detection at $m / z 348.3(\mathrm{M}+\mathrm{H})^{+}$for AEA in a time range of $0-2.6 \mathrm{~min}, \mathrm{~m} / z 396.3\left(\mathrm{M}+\mathrm{NH}_{4}\right)^{+}$for 2-AG and $1(3)$ AG over a time range of 2.6-4.0 min, and $\mathrm{m} / z 374.3\left(\mathrm{M}+\mathrm{NH}_{4}\right)^{+}$for 2-OG and 1(3)-OG in a time range of $4.0 \mathrm{~min}-7.0 \mathrm{~min}$. The Dwell time for each channel was $1.0 \mathrm{sec}$ with an interscan time of $0.1 \mathrm{sec}$. Masslynx software version 4.0 was used for system control and data processing.

\section{Calibration}

Prior to in-vitro and in-vivo evaluation of MAGL and FAAH inhibitors, the relationships between MS response and concentration of representative MAGs (e.g., 2-AG, 2-OG) and AEA in rat brain homogenate were established by spiking a series of the known amount of the reference compounds into $0.50 \mathrm{~mL}$ of rat brain homogenate (equivalent to $50 \mathrm{mg}$ of brain tissue) on ice. The spiked brain homogenate was then extracted with $6 \mathrm{~mL}$ of chloroform - methanol (2:1). The MS responses versus concentrations for these spiked rat brain homogenate samples produced linear relationships for 2-AG and 2-OG over a concentration rang of $2.5 \mathrm{nmol} / \mathrm{g}$ to $100 \mathrm{nmol} / \mathrm{g}$ with a regression coefficient $\left(\mathrm{r}^{2}\right)$ of 0.9949 and 0.9932 , respectively and for AEA over a concentration range of $0.004 \mathrm{nmol} / \mathrm{g}$ to $20 \mathrm{nmol} / \mathrm{g}$ with a $\mathrm{r}^{2}$ of 0.9997 (data not shown).

\section{Stability of 2-AG and 2-OG in the mobile phases}

$1.0 \mathrm{mM} 2$-AG or $1.0 \mathrm{mM} 2-\mathrm{OG}$ stock solutions $(10 \mu \mathrm{L})$ was added into a $2 \mathrm{~mL}$ HPLC vial containing $1.0 \mathrm{~mL}$ of each of 3 different mobile phases (i.e., A, B and C) and mixed on a vortex-mixer, and then was immediately loaded onto an auto-sampler at ambient temperature for LC / MS analysis. The mobile phase A was $50 \mathrm{mM}$ ammonium formate and $0.1 \%$ formic acid in acetonitrile - water (70:30) at pH 5.4; mobile phase $\mathrm{B}$ was $50 \mathrm{mM}$ ammonium formate in acetonitrile - water (70:30) at $\mathrm{pH} 7.0$; and mobile phase $\mathrm{C}$ was $0.1 \%$ formic acid in acetonitrile water (70:30) at $\mathrm{pH}$ 3.5. An aliquot of $10 \mu \mathrm{L}$ of each sample solution was repeatedly injected onto the LC / MS system every 20 min for $24 \mathrm{~h}$.

In-vitro AEA / 2-AG / 2-OG accumulation assay using rat brain homogenate

Mature male Sprague Dawley rats (Charles River Laboratories,
Wilmington, MA), weighing $250 \mathrm{~g}$ to $300 \mathrm{~g}$ with free access to water and standard laboratory rat chow were used for this study. The Institutional Animal Care and Use Committee (IACUC) of Janssen Research and Development, LLC approved all procedures. Under anesthesia induced with a mixture of $70 \% \mathrm{CO}_{2}$ and $30 \% \mathrm{O}_{2}$, the rats were euthanized via cardiac puncture and brains were immediately removed, frozen on dry ice and stored in a $-80^{\circ} \mathrm{C}$ freezer until use. $20 \mathrm{mM}$ 4-(2-hydroxyethyl)1-piperazineethanesulfonic acid (HEPES) buffer solution ( $\mathrm{pH} 7.4$, $10 \mathrm{~mL}$ ) containing $125 \mathrm{mM} \mathrm{NaCl}, 1 \mathrm{mM}$ ethylenediaminetetraacetic acid (EDTA), $5 \mathrm{mM} \mathrm{KCl}$ and $20 \mathrm{mM}$ glucose was added into a tube containing each gram of rat brain tissue. The brain tissue sample was homogenized using a VirTis Handishear Hand-held Homogenizer (Gardiner, NY). Aliquots of $0.5 \mathrm{~mL}$ of rat brain homogenate were transferred into $15 \mathrm{~mL}$ glass centrifuge tubes. A warmed $20 \mathrm{mM}$ HEPES buffer solution $(4.5 \mathrm{~mL})$ was added into each centrifuge tube, mixed, and then incubated at $37^{\circ} \mathrm{C}$ for $8 \mathrm{~min}$. A test compound solution $(0.001 \mu \mathrm{M}-100 \mu \mathrm{M})$ was then added into the tube, and continued to be incubated for an additional $10 \mathrm{~min}$. After an $18 \mathrm{~min}$ of incubation at $37^{\circ} \mathrm{C}$, calcium dichloride $\left(\mathrm{CaCl}_{2}\right)$ (final concentration $10 \mathrm{mM}$ ) was added (final volume $5 \mathrm{~mL}$ ) and then incubated for $12 \mathrm{~min}$ at $37^{\circ} \mathrm{C}$. To terminate the reaction, chloroform-methanol (2:1) extraction solution $(6 \mathrm{~mL})$ was added into the centrifuge tube and mixed. The bottom layer was collected into a glass culture tube. The solvent was removed under a stream of nitrogen gas. Tetrahydrofuran $(20 \mu \mathrm{L})$ was added into each tube and mixed to dissolve the residue, and then a volume $(180 \mu \mathrm{L})$ of $50 \mathrm{mM}$ ammonium formate and $0.1 \%$ formic acid in acetonitrile - water (85:15) was added and mixed. The resulting suspension was centrifuged at $7000 \times \mathrm{g}$ for $5 \mathrm{~min}$ at room temperature. The supernatant was transferred into an HPLC vial for LC / MS analysis.

Separation of the analytes was carried out on a Waters Acquity $\mathrm{UPLC}^{\mathrm{TM}} \mathrm{BEH} \mathrm{C} \mathrm{C}_{18}$ column $(2.1 \times 50 \mathrm{~mm}$, particle size $1.7 \mu \mathrm{m})$ at $40^{\circ} \mathrm{C}$. For the in-vitro studies, a LC isocratic elution was carried out with 50 $\mathrm{mM}$ ammonium formate and $0.1 \%$ formic acid in acetonitrile-water (70:30) solution ( $\mathrm{pH} \mathrm{5.4)} \mathrm{at} \mathrm{a} \mathrm{flow} \mathrm{rate} \mathrm{of} 0.25 \mathrm{~mL} / \mathrm{min}$. The sample injection volume was $10 \mu \mathrm{L}$ and the LC runtime was $7 \mathrm{~min}$. The retention time was $2.25 \mathrm{~min}$ for AEA, $2.89 \mathrm{~min}$ for $2-\mathrm{AG}, 3.11 \mathrm{~min}$ for 1(3)-AG, $4.87 \mathrm{~min}$ for 2-OG, and $5.37 \mathrm{~min}$ for 1(3)-OG.

A commercially available curve fitting software package (GraphPad Software, Inc. La Jolla, CA, 92037, USA) was used to determine halfmaximal concentration $\left(\mathrm{IC}_{50}\right.$ ) values.

\section{In-vivo rat brain endocannabinoids profiling}

Mature male Sprague Dawley rats (Charles River Laboratories, Wilmington, MA), weighing $250 \mathrm{~g}$ to $300 \mathrm{~g}$ with free access to water and standard laboratory rat chow were used for this study. The Institutional Animal Care and Use Committee (IACUC) of Janssen Research and Development, LLC approved all procedures. 1-(1-\{[3-Chloro-6(trifluoromethyl)-1-benzothiophen-2-yl] carbonyl\}azetidin-3-yl)-4(1,3-thiazol-4-ylcarbonyl) piperazine (JNJ4218734) was formulated with the vehicle $20 \%$ hydroxypropyl-beta-cyclodextrin (HP $\beta C D$ ) Eight rats per group were orally dosed (per os) at $2.5 \mathrm{~mL} / \mathrm{kg}$ of the vehicle containing $0,1,3,10$, or $30 \mathrm{mg}$ of MAGL Inhibitor A. Under anesthesia induced with a mixture of $70 \% \mathrm{CO}_{2}$ and $30 \% \mathrm{O}_{2}$, the rats were euthanized via cardiac puncture at 120 minutes after dosing. The brains were immediately removed, frozen on dry ice and stored in a $-80^{\circ} \mathrm{C}$ freezer until use. Ice-cold 200-proof ethyl alcohol containing 1.0 $\mu \mathrm{M} 2-\mathrm{AG}-\mathrm{d}_{8}$ and $0.1 \mu \mathrm{M}$ AEA- $\mathrm{d}_{8}(4 \mathrm{~mL})$ was added into a tube with each gram of rat brain tissue. The brain tissue sample was homogenized using a VirTis Handishear Hand-held Homogenizer (Gardiner, NY). An aliquot of $0.5 \mathrm{~mL}$ of the brain homogenate was transferred into a 
Citation: Caldwell GW, Lang W (2016) Profiling Rat Brain Monoacylglycerol Lipase Activity Using an Ammonia-Adduct Enhanced Selected lon Monitoring Liquid-Chromatography Positive Electrospray lonization Mass Spectrometry Assay. Pharm Anal Acta 7: 470. doi:10.4172/21532435.1000470

Page 5 of 11

microcentrifuge tube and centrifuged at $12000 \mathrm{rpm}$ for $10 \mathrm{~min}$ on an Eppendorf Bench Top Centrifuge. The supernatant was transferred into glass inserts in a 96-well plate for LC / MS analysis.

Separation of endocannabinoids was performed on a Zorbax Eclipse C 8 column $(2.1 \mathrm{~mm} \times 50 \mathrm{~mm}$, particle size $3.5 \mu \mathrm{m})$. The mobile Phase A was $25 \mathrm{mM}$ ammonium formate and $0.1 \%$ formic acid in water and $\mathrm{B}$ was $25 \mathrm{mM}$ ammonium formate and $0.1 \%$ formic acid in acetonitrile-water (85:15). A gradient elution at a flow rate of 0.3 $\mathrm{mL} / \mathrm{min}$ was used with $65-85 \% \mathrm{~B}$ in $10 \mathrm{~min}$, hold $85 \% \mathrm{~B}$ for $3 \mathrm{~min}, 85$ $65 \% \mathrm{~B}$ in $0.1 \mathrm{~min}$ and hold for $7 \mathrm{~min}$, total run time was approximately $20 \mathrm{~min}$. These LC conditions were selected to cover a larger range of endocannabinoid structural types including AEA, 2-AG, 2-OG, 2-PG, and 2-LG. The mass spectrometer $+\mathrm{ESI}$ ion source parameters were set as described above. Selected ion monitoring (SIM) was used for detection at $m / z 348.2$ for AEA $(\mathrm{M}+\mathrm{H})^{+}$, RT $6.50 \mathrm{~min}$ and 2-PG (M $\left.+\mathrm{NH}_{4}\right)^{+}$, RT $10.43 \mathrm{~min} ; m / z 396.2\left(\mathrm{M}+\mathrm{NH}_{4}\right)^{+}$for $2-\mathrm{AG}$ at RT 8.89 min; $\mathrm{m} / z 404.2\left(\mathrm{M}+\mathrm{NH}_{4}\right)^{+}$for 2 -AG-d8 at RT $8.75 \mathrm{~min} ; \mathrm{m} / z 372.2$ $\left(\mathrm{M}+\mathrm{NH}_{4}\right)^{+}$for 2-LG at RT $8.82 \mathrm{~min} ; \mathrm{m} / z 374.2\left(\mathrm{M}+\mathrm{NH}_{4}\right)^{+}$for 2-OG at RT $11.80 \mathrm{~min}$. The dwell time for each channel was $0.2 \mathrm{sec}$ with an interscan time of $0.05 \mathrm{sec}$.

\section{Results and Discussion}

\section{Formation of ammonium adduct ions}

In +ESI mode, non-nitrogen containing endocannabinoids (e.g., $\mathrm{M}=2-\mathrm{AG}, 2-\mathrm{OG})$ tended to form strong sodium $(\mathrm{M}+\mathrm{Na})^{+}$adduct ions, weak potassium $(\mathrm{M}+\mathrm{K})^{+}$adduct ions, and weak protonated $(\mathrm{M}$ $+\mathrm{H})^{+}$molecular ions in a mobile phase consisting of $0.1 \%$ formic acid in a 70:30 acetonitrile-water mixture at $\mathrm{pH} 3.5$ (Figure 2A; 2-OG data not shown). Increasing the formic acid level resulting in lower $\mathrm{pH}$ values in the mobile phase did not improve the relative $\mathrm{m} / z$ intensity of the protonated molecular cation. In addition, the formed metal adduct ions were quite stable, while the protonated molecular cation of 2 -AG could be fragmented in the +ESI source by increasing the cone voltage. It was difficult to generate subsequent product ions from the metal adduct ions by +ESI in-source CID. In the literature, SIM of the sodium adduct ions of non-nitrogen containing endocannabinoids has been reported by adding low concentration of nonvolatile sodium acetate in the mobile phase coupled with LC / +ESI / MS detection (44). Introducing a non-volatile salt in the mobile phase results in salt accumulation in the ion source over the course of sample analysis and significantly decreases the sensitivity of the assay. We found that introducing $50 \mathrm{mM}$ of ammonium formate to a mobile phase replaced the metal adducts ions with only a single ammonium adduct (Figure 2B). Under these experimental conditions, a minor unexpected formamide adduct cation $\left(\mathrm{MH}+\mathrm{HCONH}_{2}\right)^{+}$was detected for 2-AG and AEA and an ammonium and formamide adduct cation $\left(\mathrm{MNH}_{4}\right.$ $\left.+\mathrm{HCONH}_{2}\right)^{+}$for 2-OG (Figure 3). The formation of formamide in the LC / MS system may be an artifact derived from the dehydration of ammonium formate on the hot surfaces in the ESI source. With a mild cone voltage, the formed ammonium adduct ions of non-nitrogen containing endocannabinoids were stable and could be detected using SIM mode. Different from 2-AG and 2-OG, AEA containing an amide nitrogen atom predominantly formed a protonated molecular cation under both conditions with or without ammonium formate in the mobile phases. The SIM detection of ammonium-adduct cations for
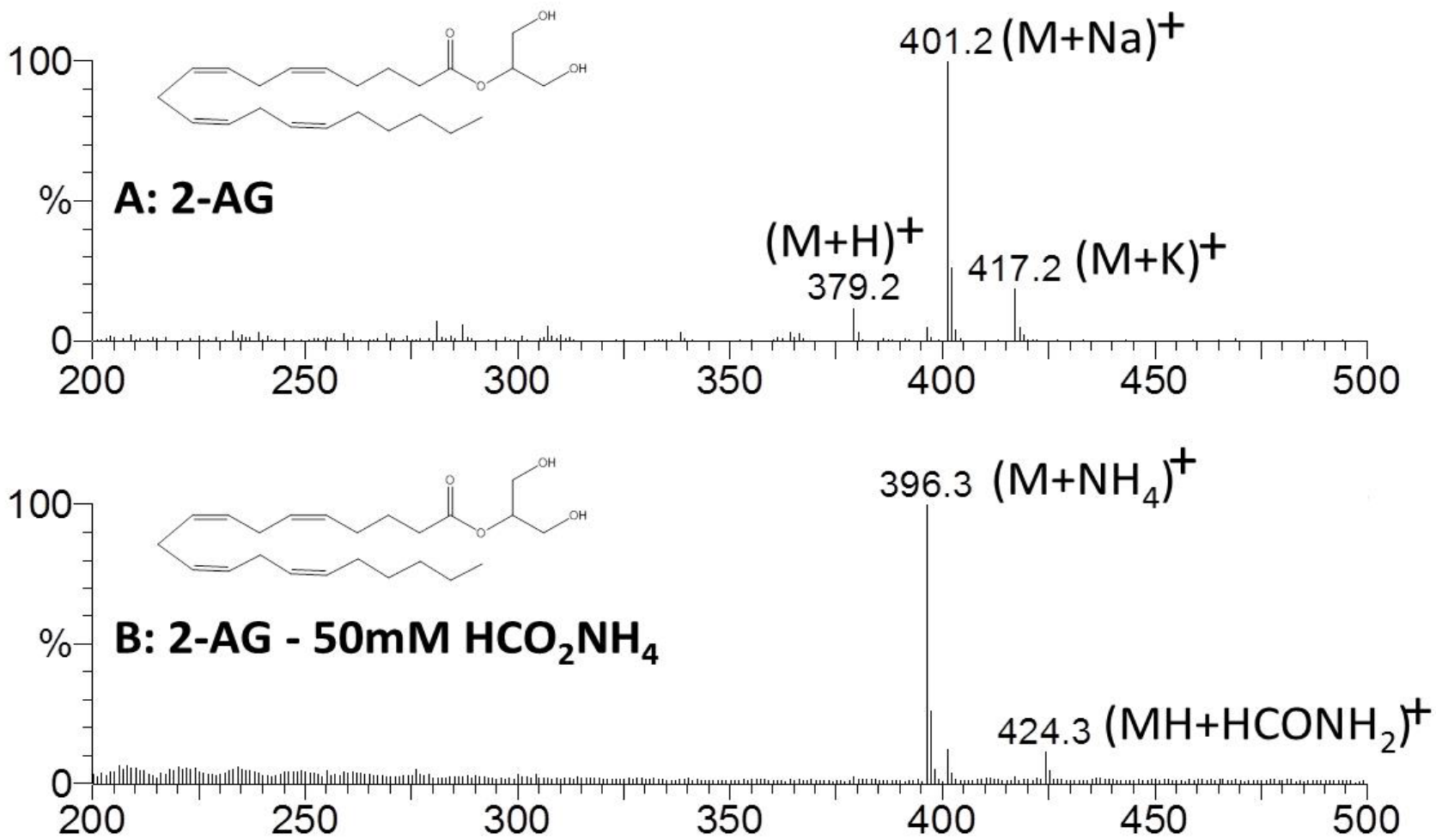

Figure 2: Q1 full scan mass spectra of 2-AG in various solutions. A: 2-AG in 0.1\% formic acid / acetonitrile-water (70:30), pH 3.5, predominant molecular sodium adduct formation $(\mathrm{M}+\mathrm{Na})^{+}$together with a minor protonated molecular ion $(\mathrm{M}+\mathrm{H})^{+}$and a potassium adduct ion $(\mathrm{M}+\mathrm{K})^{+}$. $\mathrm{B}: 2-\mathrm{AG}$ in $50 \mathrm{mM}$ ammonium formate and $0.1 \%$ formic acid in acetonitrile-water (70:30), $\mathrm{pH} 5.4$, forced ammonium adduct formation together with a minor sodium adduct at $401.2 \mathrm{~m} / \mathrm{z}$ and protonated formamide adduct ion $\left(\mathrm{MH}+\mathrm{HCONH}_{2}\right)^{+}$. 
Citation: Caldwell GW, Lang W (2016) Profiling Rat Brain Monoacylglycerol Lipase Activity Using an Ammonia-Adduct Enhanced Selected lon Monitoring Liquid-Chromatography Positive Electrospray lonization Mass Spectrometry Assay. Pharm Anal Acta 7: 470. doi:10.4172/21532435.1000470

Page 6 of 11
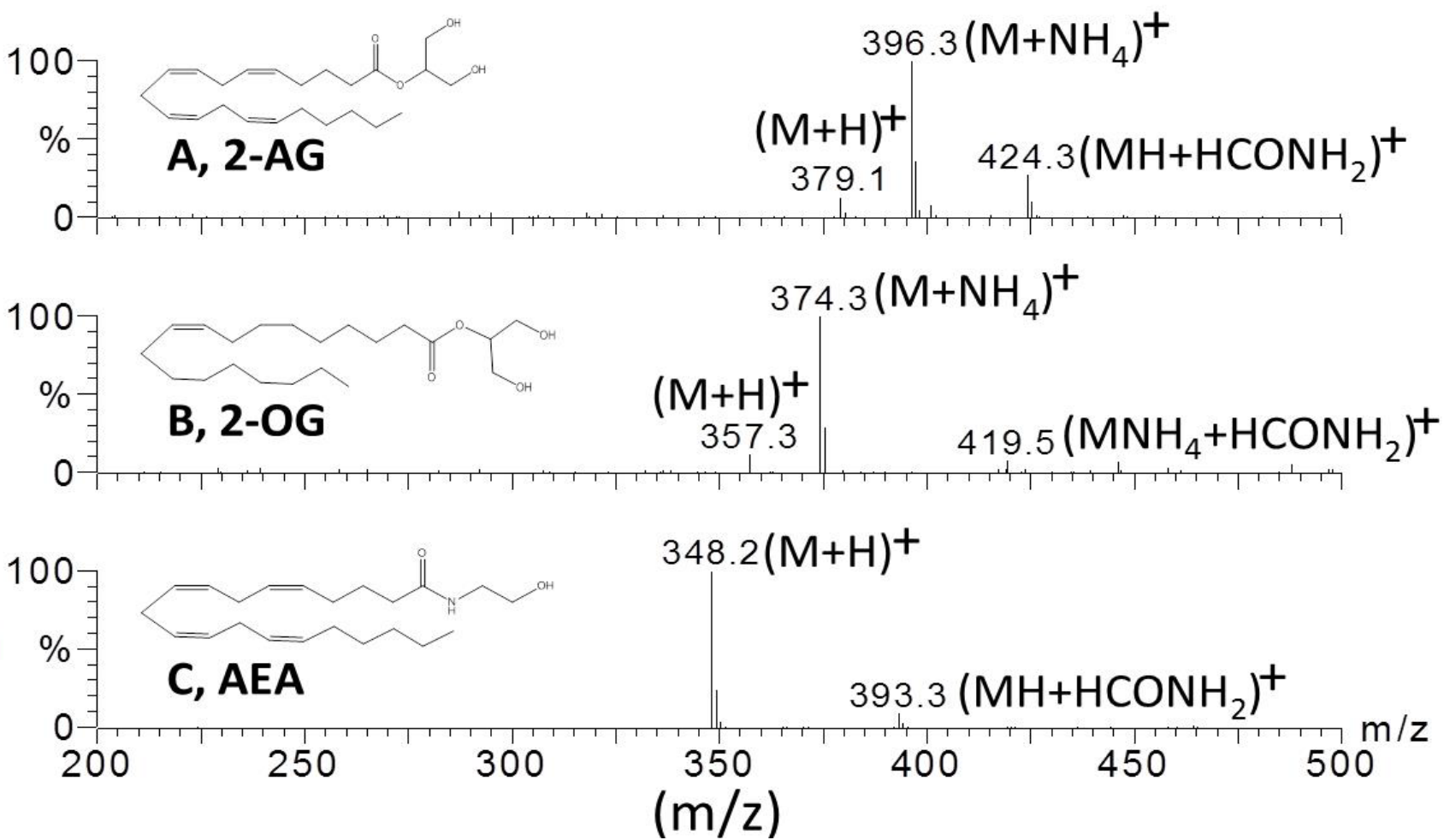

Figure 3: Q1 full scan mass spectra of 2-AG (A), 2-OG (B) and AEA (C) in $50 \mathrm{mM}$ ammonium formate and $0.1 \%$ formic acid in acetonitrile-water (70:30), pH 5.4. Under these experimental conditions, the major cations for 2-AG and 2-OG are the ammonium adducts while the protonated molecular ion is the major cation for $A E A$.

non-nitrogen containing endocannabinoids (e.g., 2-AG, 2-OG) and the protonated molecular cation for AEA can be used in brain in-vitro and in-vivo evaluation of MAGL inhibitors. The application of ammoniumadduct cations as the precursors for +ESI MRM detection to analyze of prostaglandin glyceryl esters has been previously reported (45).

\section{Acyl migration of 2-MAGs}

During the incubation with rat brain homogenate in an aqueous medium, the chemical acyl migration of 2-MAGs to 1(3)-MAGs may occur following the enzymatic formation of 2-MAGs. The kinetics and mechanism of the non-enzyme mediated acyl migration of 2-MAGs in protic solvents have been previously investigated by Rouzer et al. [42]. Each pair of 2- and 1(3)-MAGs yield isobaric cations and cannot be differentiated by MS detection. Therefore, LC separation of the pair of acyl isomers for each MAG is necessary for accessing the degree of acyl migration during the in-vitro MAGL activity assay (Figure 4). To minimize the chemical degradation of 2-MAGs during the incubation and LC / MS analysis, the stability of 2-AG and 2-OG at different $\mathrm{pH}$ values was investigated using a simple LC / MS method. The results of $\%$ remaining of 2-AG in 3 different mobile phases at ambient temperature over $24 \mathrm{~h}$ are given in Figure 5. It was found that 2-AG was stable with more than $98 \%$ of the parent remaining over a $24 \mathrm{hr}$ period in a mobile phase composed of $50 \mathrm{mM}$ ammonium formate and $0.1 \%$ formic acid in a 70:30 acetonitrile-water mixture at $\mathrm{pH}$ 5.4. In a mobile phase containing $50 \mathrm{mM}$ ammonium formate in acetonitrile-water (70:30) at $\mathrm{pH} 7.0$, significant degradation of $2-\mathrm{AG}$ was observed with $85.5 \%$ of the parent remaining over the course of the study. Time-dependent linear increase of 1(3)-AG levels was detected in this sample, indicating the degradation was mainly due to acyl migration. In the presence of $0.1 \%$ formic acid in acetonitrile-water (70:30) at $\mathrm{pH} 3.5,2-\mathrm{AG}$ underwent rapid degradation with $82 \%$ of the parent remaining in the first hour of incubation at ambient temperature, and then establishing equilibrium after $4 \mathrm{~h}$. No detectable level of 1(3)-AG was observed in this sample over the course of testing, suggesting the degradation may go through a hydrolysis mechanism producing arachidonic acid and glycerol under extreme acidic conditions ( $\mathrm{pH}$ 3.5). Similar results were also obtained for 2-OG under these experimental conditions (data not shown). Reducing the $50 \mathrm{mM}$ ammonium format concentration to 25 $\mathrm{mM}$ in the three mobile phases at the same $\mathrm{pH}$ values showed similar degradation. These results clearly indicate that the selection of mobile phase conditions near $\mathrm{pH} 5.4$ is absolutely necessary for overnight LC / MS runs. Based on these findings, the mobile phase with $50 \mathrm{mM}$ ammonium formate and $0.1 \%$ formic acid in acetonitrile-water (70:30) was chosen for LC isocratic elution for the in-vitro rat brain MAGL inhibitory assay and $25 \mathrm{mM}$ ammonium format and $0.1 \%$ formic acid in water (A) and acetonitrile (B) for a LC gradient elution in brain endocannabinoids profiling in-vivo assay. It is believed that the 1(3)acyl isomers of 2-MAGs were mainly formed during sample collection, preparation and analysis, therefore, a sum of both 2-MAG and 1(3)MAG levels was used for reporting each MAG level in the in-vivo brain endocannabinoids profiling assay.

\section{AEA and 2-MAGs accumulation in rat brain homogenate in the presence of MAGL and FAAH inhibitors}

There are several enzymes in the rat brain that potentially uses 2-MAGs as a substrate, e.g., FAAH, MAGL, cyclooxygenase-2 (COX2 ), and MGL kinase [16-18]. In order to confirm the utility of the ammonia adduct SIM LC / +ESI / MS method for endocannabinoid profiling, this approach was used to investigate the primary roles of 


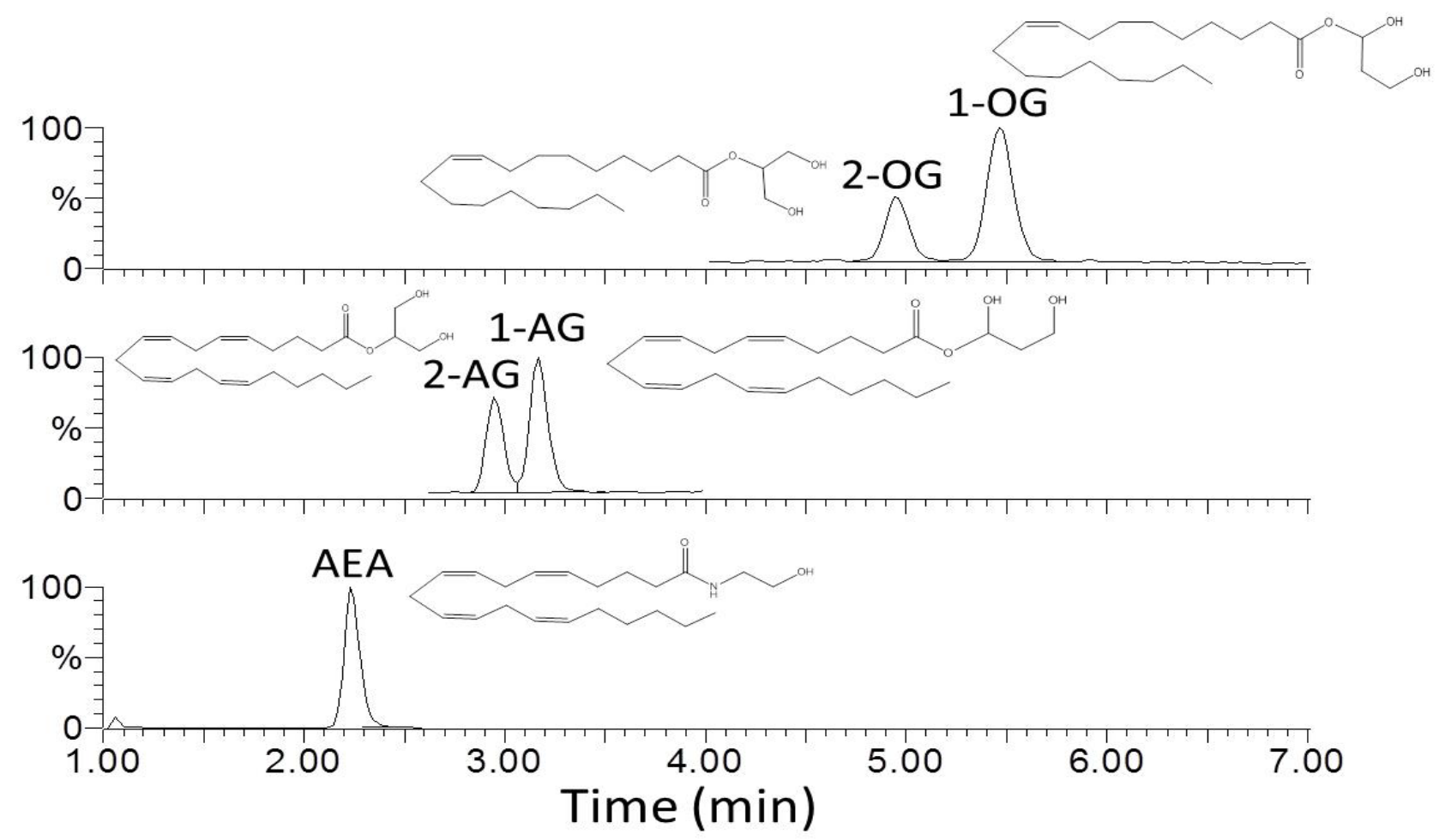

Figure 4: Representative selected ion monitoring (SIM) chromatograms of AEA, 1(3)-AG, 2-AG, 1(3)-OG and 2-OG at $1 \mu$ M each on a Waters Acquity BEH $C_{18}$ column $(2.1 \mathrm{~mm} \times 50 \mathrm{~mm})$ eluted isocratically using the mobile phase: $50 \mathrm{mM}$ ammonium formate and $0.1 \%$ formic acid in acetonitrile-water $(70: 30), \mathrm{pH} 5.4$.

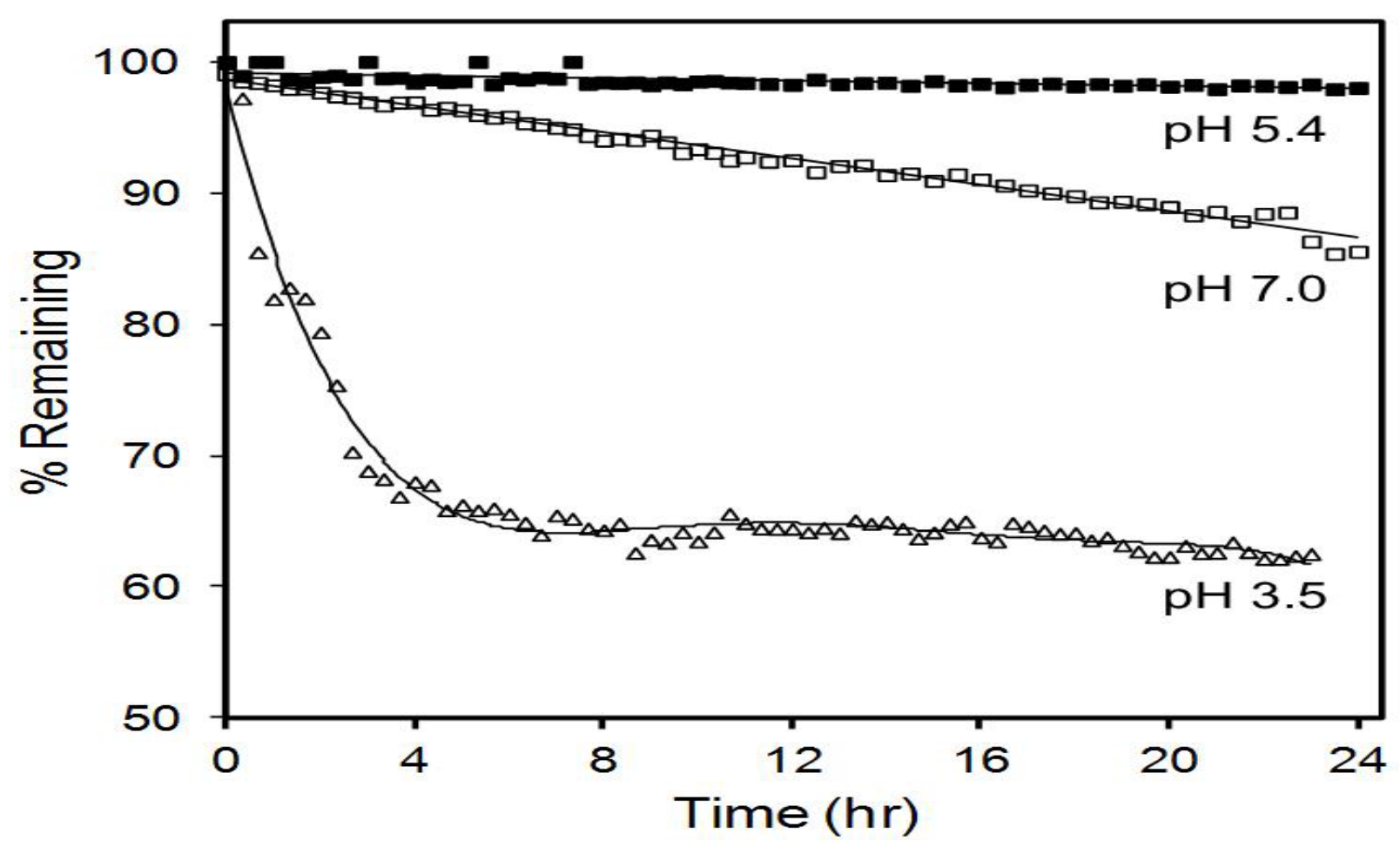

Figure 5: Stability of 2-AG in 3 different mobile phases: A. solid square (a), $50 \mathrm{mM}$ ammonium formate and $0.1 \%$ formic acid in acetonitrile - water (7:3), pH 5.4; B. open square $(\square), 50 \mathrm{mM}$ ammonium formate in acetonitrile, $\mathrm{pH} 7.0$; $\mathrm{C}$. open triangle $(\Delta), 0.1 \%$ formic acid in acetonitrile - water $(7: 3)$, pH 3.5 . 
Citation: Caldwell GW, Lang W (2016) Profiling Rat Brain Monoacylglycerol Lipase Activity Using an Ammonia-Adduct Enhanced Selected lon Monitoring Liquid-Chromatography Positive Electrospray lonization Mass Spectrometry Assay. Pharm Anal Acta 7: 470. doi:10.4172/21532435.1000470

Page 8 of 11

MAGL and FAAH in the deactivation of 2-MAGs and AEA in rat brain, respectively. The MAGL inhibitors MAFP and URB602 and the FAAH inhibitor URB597 were evaluated using the in-vitro assay described in the experimental section [30]. The results showed that the 2 -AG level in rat brain homogenate increased approximately 33 -fold after treatment with $10 \mu \mathrm{M}$ MAFP (inset Figure 6) and approximately 5 -fold for URB602 $(100 \mu \mathrm{M})$ in comparison with the vehicle control level at $0.75 \mathrm{nmol} / \mathrm{g}$ (Figure 6). Similar fold-differences were observed for 1(3)-AG suggesting that acyl migration of 2-AG to 1(3)-AG had occurred during the analysis. The level of 2-OG was below the detection limits in the vehicle; however, upon inhibition of MAGL with MAFP and URB602, the levels of 2-OG, and the acyl migration 1(3)-OG were detected in the brain homogenate. The AEA level in the brain homogenate increased approximately 1.2 -fold after treatment with MAFP $(10 \mu \mathrm{M})$ and decreased approximately $50 \%$ after treatment with URB602 $(100 \mu \mathrm{M})$ in comparison with the vehicle control level at $0.06 \mathrm{nmol} / \mathrm{g}$ (Figure 6). Under these experimental conditions, the nonselective irreversible inhibitor MAFP inhibited both FAAH and MAGL which was in accordance with others studies in the literature [33]. The non-competitive reversible inhibitor URB602 inhibited only MAGL in our study which was consistent with the literature where URB602 has been measured to inhibit native rat brain MAGL with an $\mathrm{IC}_{50}$ value of $28 \mu \mathrm{M} \pm 4 \mu \mathrm{M}[32,45,46]$. In the presence of $10 \mu \mathrm{M}$ of the irreversible FAAH inhibitor URB597 ( $\mathrm{IC}_{50}$ approximately $0.01 \mu \mathrm{M}$ ) [30,46], the AEA level in the brain homogenate increased approximately 1.4 -fold and the levels of 2-AG increased by 1.7 -fold as compared to vehicle control levels. The presence of 2-AG, 1(3)-AG, 2-OG, and 1(3)-OG in the brain homogenate, after treatment with URB597 $(10 \mu \mathrm{M})$, suggested that the irreversible FAAH inhibitor was also inhibiting MAGL. In the literature, URB597 is reported to be a selective irreversible inhibitor of FAAH $[30,31,46]$. Since URB597 is an irreversible inhibitor, it may be binding to MAGL due to the high URB597 concentration $(10 \mu \mathrm{M})$ used in the current accumulation assay.

To further evaluate the ammonia adduct SIM LC / +ESI / MS method, JNJ4218734 a known MAGL inhibitor was selected [29,47]. An in-vitro concentration-dependent 2-AG accumulation study was performed in rat brain homogenate in the presence of JNJ4218734 and the results are shown in Figure 7. The fold increase levels of 2-AG shown in Figure 7 are the combination of 2-AG and 1(3)-AG levels as compared to their vehicle controls. No significant increase of AEA was observed as compared to vehicle control with increasing concentrations of JNJ4218734. Based on the combination 2-AG / 1(3)AG accumulation rat brain homogenate data, an $\mathrm{IC}_{50}$ value of $0.26 \mu \mathrm{M}$ was obtained for the JNJ4218734 compound by curve-fitting. This combination $\mathrm{IC}_{50}$ value and the selectivity of the JNJ4218734 compound for the MAGL enzyme over the FAAH enzyme are consistent with a previous accumulation rat brain study using JNJ4218734 [47].

The above AEA and 2-MAGs accumulation rat brain homogenate studies, using a selection of FAAH and MAGL inhibitors, demonstrated that the SIM LC / +ESI / MS ammonium replacement approach to force non-nitrogen containing endocannabinoid metal-adduct $(\mathrm{M}+$ $\mathrm{X})^{+}(\mathrm{X}=\mathrm{Na}, \mathrm{K})$ cations to an ammonium-adduct $\left(\mathrm{M}+\mathrm{NH}_{4}\right)^{+}$cation formation by adding $50 \mathrm{mM}$ ammonium formate in the LC mobile phase is acceptable for in-vitro evaluation of inhibitory potency of MAGL and FAAH inhibitors.

\section{kBrain MAG accumulation in rats treated with MGL inhibitors}

To investigate the ammonia adduct SIM LC / +ESI / MS method for in-vivo endocannabinoid profiling, the in-vivo dose-response of rat brain endocannabinoids treated with the JNJ4218734 compound were measured in Sprague Dawley rats treated with a single oral dose at 0, 1, 3, 10 and $30 \mathrm{mg} / \mathrm{kg}$. As shown in Figure 8, after $120 \mathrm{~min}$ of JNJ4218734

\section{AEA 2-AG 闵1-AG 目2-OG Ð1-OG}

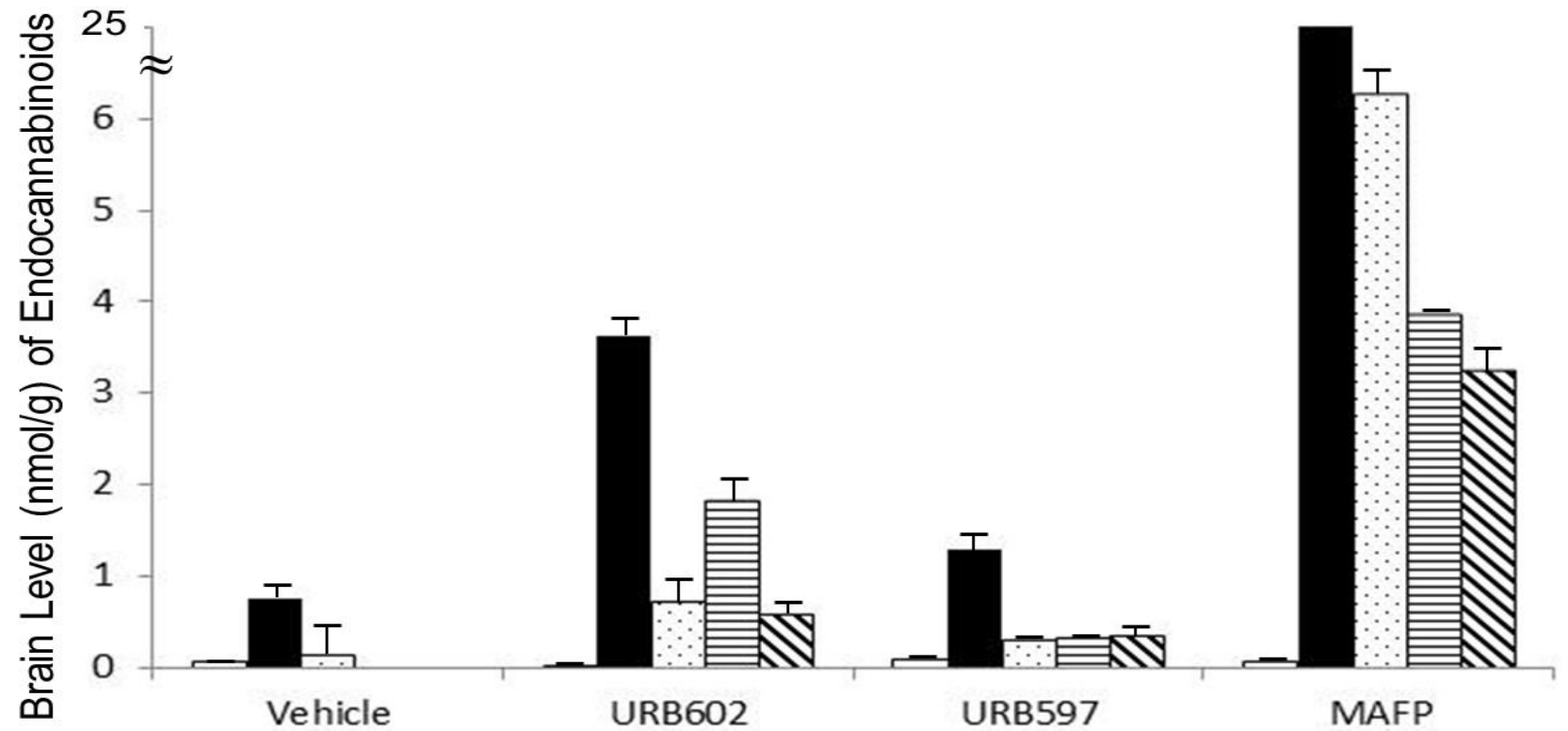

Figure 6: In-vitro responses of major endocannabinoids (2-AG, 1(3)-AG, 2-OG and 1(3)-OG) in rat brain homogenate treated with various inhibitors, $100 \mu \mathrm{M}$ URB602 (MAGL inhibitor), $10 \mu \mathrm{M}$ URB597 (FAAH inhibitor), and $10 \mu \mathrm{M}$ MAFP (MAGL inhibitor). Data represent the mean of 3 independent experiments. 
<smiles>NC(=O)c1cccc(-c2cccc(OC(=O)NC3CCCCC3)c2)c1</smiles>

URB597<smiles>O=C(Nc1cccc(-c2ccccc2)c1)OC1CCCCC1</smiles>

URB602

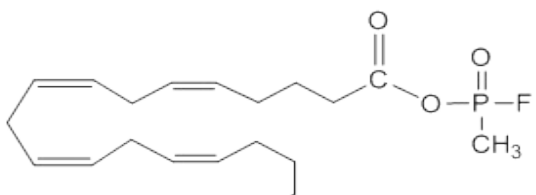

MAFP

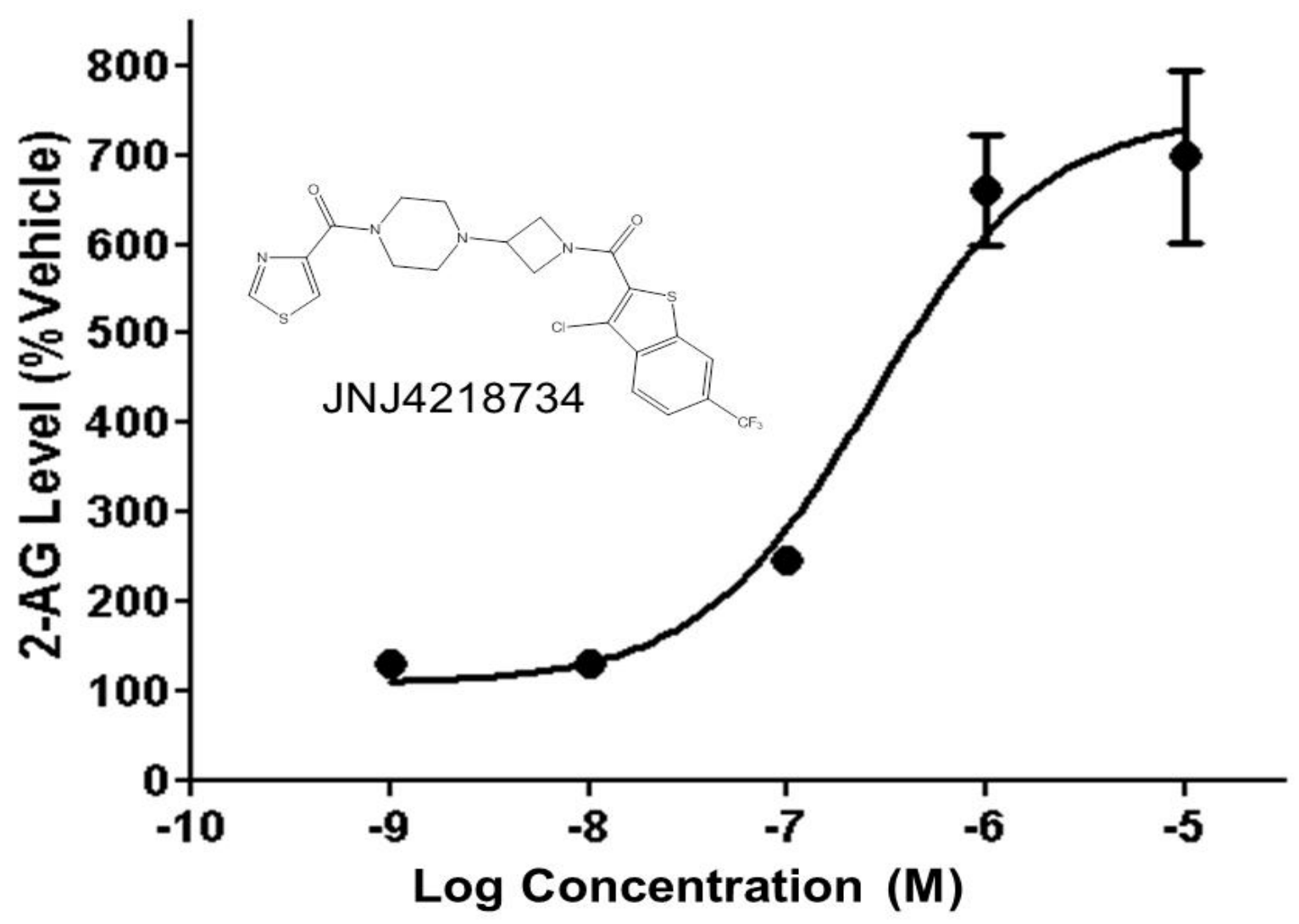

Figure 7: Concentration dependent 2-AG accumulation in rat brain homogenate in the presence of JNJ4218734. Data represents the average of 2 independent experiments $(\mathrm{n}=3$ each).

compound exposure, the brain dose-response accumulation of 4 major MAGs (i.e., 2-AG, 2-OG, 2-PG and 2-LG), as well as AEA was measured using the ammonia adduct SIM LC / +ESI / MS approach. The brain levels of 2-AG and 2-OG are a combination of their acyl migration products (i.e., 1(3)-AG and 1(3)-OG). The average brain levels of 2-AG / 1(3)-AG were 12.4, 17.6, 19.9, 39.3 and $66.2 \mathrm{nmol} / \mathrm{g}$ for the vehicle controls, $1,3,10$ and $30 \mathrm{mg} / \mathrm{kg}$-dosed groups, respectively. In addition, 2-OG / 1(3)-OG was the second important MAG in the rat brain in terms of concentration response at 8.86, 12.3, 17.6, 25.3 and $35.4 \mathrm{nmol} / \mathrm{kg}$ to the dose levels of $0,1,3,10$ and $30 \mathrm{mg} / \mathrm{kg}$, respectively.
The brain levels of AEA were 1000-folds less than the MAG levels in a pmol/g range. The average brain levels of AEA were 3.12, 4.14, $4.85,4.95$ and $4.70 \mathrm{pmol} / \mathrm{g}$ in the rats dosed at $0,1,3,10$ and $30 \mathrm{mg} /$ $\mathrm{kg}$, respectively. Thus, a dose-dependent accumulation of the 4 major brain MAGs in these rats was observed and a non-dose-dependent accumulation of AEA was observed indicating that the JNJ4218734 compound was inhibiting MAGL and not FAAH. These results are consistent with the literature [47] and demonstrated that the SIM LC / +ESI / MS ammonium replacement approach can be used in in-vivo studies as a target engagement biomarker assay. 
Citation: Caldwell GW, Lang W (2016) Profiling Rat Brain Monoacylglycerol Lipase Activity Using an Ammonia-Adduct Enhanced Selected lon Monitoring Liquid-Chromatography Positive Electrospray lonization Mass Spectrometry Assay. Pharm Anal Acta 7: 470. doi:10.4172/21532435.1000470

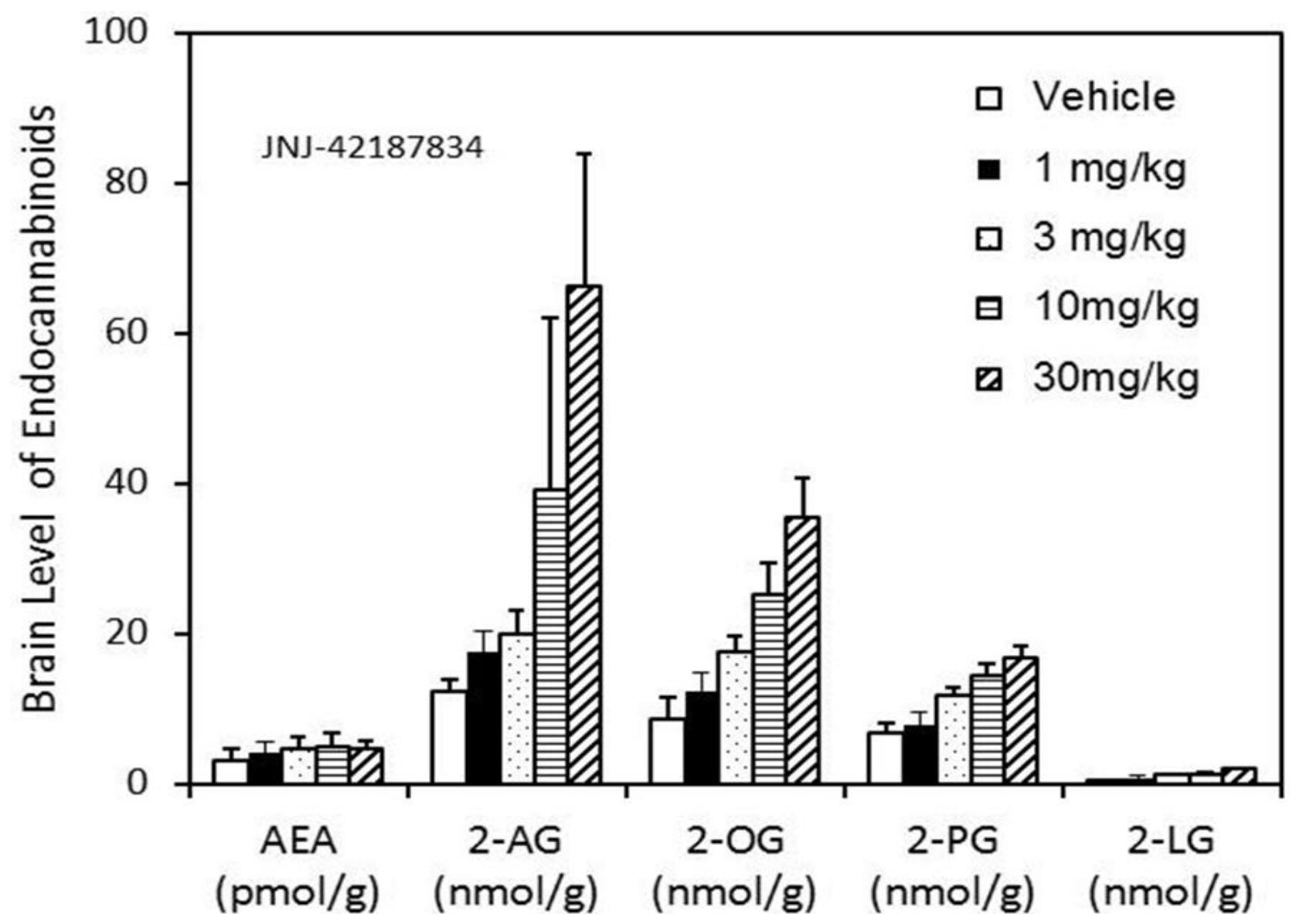

Figure 8: Dose responses of rat brain major endocannabinoids (AEA, 2-AG, 2-OG, 2-PG and 2-LG) in rats treated with various oral single doses of JNJ4218734 at 0 , $0.3,1,3,10$ and $30 \mathrm{mg} / \mathrm{kg}$. The data represents a mean $\pm \mathrm{SEM}, \mathrm{n}=8$ per group.

\section{Conclusion}

Simple and efficient ammonia adduct SIM LC / +ESI / MS methods were developed for determination of rat brain endocannabinoids. The methods were applied to in-vitro rat brain homogenate studies for the evaluation of inhibitory potency of MAGL and FAAH inhibitors including MAFP, URB602, URB597 and JNJ4218734 and to in-vivo target engagement assessment of brain homogenate of JNJ4218734 in rats receiving a single oral dose of the MAGL inhibitor. Our results demonstrated that the SIM LC / +ESI / MS methods for brain endocannabinoid profiling can be used not only for in-vitro evaluation of inhibitory potency of MAGL and FAAH inhibitors, but also for invivo assessment of target engagement and proof of concept studies.

\section{Acknowledgement}

The authors gratefully thank Dennis Stone, Michael Brandt and Sui-Po Zhang for their excellent in-life work on dosing the animals and collecting brain samples.

\section{References}

1. Velayudhan L, Van Diepen E, Marudkar M, Hands O, Suribhatla S (2014) Therapeutic Potential of Cannabinoids in Neurodegenerative Disorders: A Selective Review, Current Pharmaceutical Design 20: 2218-2230.

2. Zajkowska ZE, Englund A, Zunszain PA (2014) Towards a personalized treatment in depression: endocannabinoids, inflammation and stress response, Pharmacogenomics 15: 687-698.

3. De Laurentiis A, Araujo HA, Rettori V (2014) Role of the endocannabinoid system in the neuroendocrine responses to inflammation. Curr Pharm Des 20 4697-4706.

4. BisognoT, Di Marzo V (2013) Alterations in the endocannabinoid system as a link between unbalanced energy homeostasis, neuroinflammation, and neurological and neuropsychiatric disorders, Metabolic Syndrome and Neurological Disorders 219-233.

5. Burston JJ, Woodhams SG (2014) Endocannabinoid system and pain: an introduction. Proc Nutr Soc 73: 106-117.

6. Martins CJ, Genelhu V, Di Marzo V, Francischetti EA (2014) The endocannabinoid system--back to the scene of cardiometabolic risk factors control? Horm Metab Res 46: 529-536.

7. Piomelli $D(2005)$ The endocannabinoid system: a drug discovery perspective. Curr Opin Investig Drugs 6: 672-679.

8. Pacher P, Batkai S, Kunos G (2006) The endocannabinoid system as an emerging target of pharmacotherapy. Pharmacol Rev 58: 389-462.

9. Fezza F, Bari M, Florio R, Talamonti E, Feole M, et al. (2014) Endocannabinoids, related compounds and their metabolic routes. Molecules 19: 17078-17106.

10. Mechoulam R, Fride E, Di Marzo V (1998) Endocannabinoids. Eur J Pharmacol 359: 1-18.

11. Ho WS, Barrett DA, Randall MD (2008) 'Entourage' effects of $\mathrm{N}$-palmitoylethanolamide and $\mathrm{N}$-oleoylethanolamide on vasorelaxation to anandamide occur through TRPV1 receptors. Br J Pharmacol 155: 837-846.

12. Felder CC, Briley EM, Axelrod J, Simpson JT, Mackie K, et al. (1993) Anandamide, an endogenous cannabimimetic eicosanoid, binds to the cloned human cannabinoid receptor and stimulates receptor-mediated signal 
Citation: Caldwell GW, Lang W (2016) Profiling Rat Brain Monoacylglycerol Lipase Activity Using an Ammonia-Adduct Enhanced Selected lon Monitoring Liquid-Chromatography Positive Electrospray lonization Mass Spectrometry Assay. Pharm Anal Acta 7: 470. doi:10.4172/21532435.1000470

Page 11 of 11

transduction. Proc Natl Acad Sci USA 44: 7656-7660.

13. Sugiura T, Kondo S, Sukagawa A, Nakane S, Shinoda A, et al. (1995) 2-Arachidonoylgylcerol: a possible endogenous cannabinoid receptor ligand in brain. Biochem Biophys Res Commun 215: 89-97.

14. Devane WA, Hanus L, Breuer A, Pertwee RG, Stevenson LA, et al. (1992) Isolation and structure of a brain constituent that binds to the cannabinoid receptor. Science 258: 1946-1949.

15. Liu RZ, Mita R, Beaulieu M, Gao Z, Godbout R (2010) Fatty acid binding proteins in brain development and disease. Int J Dev Biol 54: 1229-1239.

16. Giuffrida A, Beltramo M, Piomelli D (2001) Mechanisms of endocannabinoid inactivation: biochemistry and pharmacology. J Pharmacol Exp Ther 298: 7-14.

17. Dinh TP, Freund TF, Piomelli D (2002) A role for monoglyceride lipase in 2-arachidonoylglycerol inactivation. Chem Phys Lipids 121: 149-158.

18. Blankman JL, Simon GM, Cravatt BF (2007) A comprehensive profile of brain enzymes that hydrolyze the endocannabinoid 2-arachidonoylglycerol. Chem Biol 14: 1347-1356.

19. Lang W, Qin C, Lin S, Khanolkar AD, Goutopoulos A, et al. (1999) Substrate specificity and stereoselectivity of rat brain microsomal anandamide amidohydrolase. J Med Chem 42: 896-902.

20. Cadas H, di Tomaso E, Piomelli D (1997) Occurrence and biosynthesis of endogenous cannabinoid precursor, $\mathrm{N}$-arachidonoyl phosphatidylethanolamine, in rat brain. J Neurosci 17: 1226-1242.

21. Dinh TP, Kathuria S, Piomelli D (2004) RNA interference suggests a primary role for monoacylglycerol lipase in the degradation of the endocannabinoid 2-arachidonoylglycerol. Mol Pharmacol 66: 1260-1264.

22. Savinainen JR, Kansanen E, Pantsar T, Navia-Paldanius D, Parkkari T, et al. (2014) Robust hydrolysis of prostaglandin glycerol esters by human monoacylglycerol lipase (MAGL). Mol Pharmacol 86: 522-535.

23. Davis MP (2014) Cannabinoids in pain management: CB1, CB2 and nonclassic receptor ligands. Expert Opin Investig Drugs 23: 1123-1140.

24. Crowe MS, Nass SR, Gabella KM, Kinsey SG (2014) The endocannabinoid system modulates stress, emotionality, and inflammation. Brain Behav Immun 42: 1-5.

25. Jager G, Witkamp RF (2014) The endocannabinoid system and appetite: relevance for food reward. Nutr Res Rev 27: 172-185.

26. Petrosino S, Di Marzo V (2010) FAAH and MAGL inhibitors: therapeutic opportunities from regulating endocannabinoid levels. Current Opinion in Investigational Drugs 11: 51-62.

27. Vandevoorde $S$ (2008) Overview of the chemical families of fatty acid amide hydrolase and monoacylglycerol lipase inhibitors. Curr Top Med Chem 8: 247267.

28. Bisogno T1, Maccarrone M (2013) Latest advances in the discovery of fatty acid amide hydrolase inhibitors. Expert Opin Drug Discov 8: 509-522.

29. Bian H, Chevalier KM, Connolly PJ, Flores CM, Lin S, et al. (2010) Piperazinylazetidinyl diamides as monoacylglycerol lipase inhibitors and their preparation and use in the treatment of diseases. US Patent \# WO 2010124114.

30. Jayamanne A, Greenwood R, Mitchell VA, Aslan S, Piomelli D, et al. (2006) Actions of the FAAH inhibitor URB597 in neuropathic and inflammatory chronic pain models. Br J Pharmacol 147: 281-288.

31. Kwilasz AJ, Abdullah RA, Poklis JL, Lichtman AH, Negus SS (2014) Effects of the fatty acid amide hydrolase inhibitor URB597 on pain-stimulated and paindepressed behavior in rats. Behav Pharmacol 25: 119-129.

32. Szabo M, Agostino M, Malone DT, Yuriev E, Capuano B (2011) The design, synthesis and biological evaluation of novel URB602 analogues as potential monoacylglycerol lipase inhibitors. Bioorganic \& Medicinal Chemistry Letters 21: $6782-6787$

33. Deutsch DG, Omeir R, Arreaza G, Salehani D, Prestwich GD, et al. (1997) Methyl arachidonyl fluorophosphonate: a potent irreversible inhibitor of anandamide amidase. Biochemical Pharmacology 53: 255-260.

34. Hardison S, Weintraub ST, Giuffrida A (2006) Quantification of endocannabinoids in rat biological samples by GC / MS: Technical and theoretical considerations, Prostaglandins and Other Lipid Mediators 81: 106-112.

35. Muccioli GG, Stella N (2008) An optimized GC-MS method detects nanomolar amounts of anandamide in mouse brain. Anal Biochem 373: 220-228.

36. Chen J, Paudel KS, Derbenev AV, Smith BN, Stinchcomb AL (2009) Simultaneous Quantification of Anandamide and Other Endocannabinoids in Dorsal Vagal Complex of Rat Brainstem by LC-MS, Chromatographia 69: 1-7.

37. Zoerner AA, Gutzki FM, Suchy MT, Beckmann B, Engeli S, et al. (2009) Targeted stable-isotope dilution GC-MS/MS analysis of the endocannabinoid anandamide and other fatty acid ethanol amides in human plasma. J Chromatogr B Analyt Technol Biomed Life Sci 877: 2909-2923.

38. Gachet MS, Rhyn P, Bosch OG, Quednow BB, Gertsch J (2015) A quantitiative LC-MS/MS method for the measurement of arachidonic acid, prostanoids endocannabinoids, $\mathrm{N}$-acylethanolamines and steroids in human plasma Journal of chromatography. B, Analytical technologies in the biomedical and life sciences 976-977.

39. Sergi M, Battista N, Montesano C, Curini R, Maccarrone M, et al. (2013) Determination of the two major endocannabinoids in human plasma by $\mu$-SPE followed by HPLC-MS / MS. Anal Bioanal Chem 405: 785-793.

40. Zoerner AA, Gutzki FM, Batkai S, May M, Rakers C (2011) Quantification of endocannabinoids in biological systems by chromatography and mass spectrometry: a comprehensive review from an analytical and biological perspective, Biochim Biophys Acta 1811: 706-723.

41. Kebarle P, Verkerk UH (2009) Electrospray: from ions in solution to ions in the gas phase, what we know now. Mass Spectrom Rev 28: 898-917.

42. Rouzer CA, Ghebreselasie K, Marnett LJ (2002) Chemical stability of 2-arachidonylglycerol under biological conditions. Chem Phys Lipids 119: 6982.

43. Vogeser M, Schelling G (2007) Pitfalls in measuring the endocannabinoid 2-arachidonoyl glycerol in biological samples. Clin Chem Lab Med 45: $1023-$ 1025.

44. Kozak KR, Rowlinson SW, Marnett LJ (2000) Oxygenation of the endocannabinoid, 2-arachidonylglycerol, to glyceryl prostaglandins by cyclooxygenase-2. J Biol Chem 275: 33744-33749.

45. Kingsley PJ, Rouzer CA, Saleh S, Marnett LJ (2005) Simultaneous analysis of prostaglandin glyceryl esters and prostaglandins by electrospray tandem mass spectrometry. Anal Biochem 343: 203-211.

46. Piomelli D, Duranti A, Tontini A, Mor M, Tarzia G, et al (2006) URB602 and othe compounds, methods, and compositions for modulation of monoacylglycerol lipase, pain, and stress-related disorders, PCT Int Appl, WO 2006116773 A2 20061102.

47. Connelly M, Flores CM, Macielag MJ (2013) Monoacylglycerol lipase inhibitors for the treatment of metabolic diseases and related disorders, PCT Int Appl, WO 2013049293 A1 20130404 